\title{
Methodological Considerations on Tool for Researching the Challenges of Teacher Leadership through Learning Co-Creation with the Learner at School
}

\author{
${ }^{1}$ Vilma Zydziunaite, ${ }^{2}$ Lina Kaminskiene, ${ }^{3}$ Vaida Jurgile \\ ${ }^{1,3}$ Vytautas Magnus University, Academy of Education, Institute of Educational Research, \\ Lithuania \\ ${ }^{2}$ Vytautas Magnus University, Academy of Education, Lithuania
}

\begin{abstract}
Aim is to share methodological considerations on creating and using the specific tool for particular research study. A questionnaire on challenges in teacher leadership used in 2019 with the sample of 418 teachers. The tool is based on the Four Models of Teacher Leadership (Angelle, DeHart, 2016) and the concept of School Leaders (Mulford, 2003). The demographic part (28 items) ir based on the research of Gunter (2001), Gumede (2011), and Sawalhi, Chaaban (2019). The leadership part is based on the research of Laferrière, Breuleux (2002), Margolis,

Doring (2012), Alsalahi (2014), Alegado (2018), Gordon, Solis (2018) and consisted of 7 topics (time distribution, professional development; feedback; positive self-esteem; activities at school; stress factors at achool; teaching in a classroom), 11 questions, 106 items.

The internal consistency reliability (Cronbach's $\alpha$ ) coefficients for items of the separate scales of the questionnaire were calculated and the following estimates were obtained: $\alpha=.898$ for Time Distribution, $\alpha=.911$ for Professional Development, $\alpha=.798$ for Feedback, $\alpha=.876$ for Positive Self-esteem in Teaching, $\alpha=.843$ for Positive Self-esteem at School, $\alpha=.792$ for Activities at School, $\alpha=.835$ for Stress Factors at School, and $\alpha=.811$ for Teaching in a Classroom. All these values are higher than .7. Thus the data were reliable and it was not necessary to exclude any scale estimates from further analysis.

Ethics and validity of the tool was assessed and an ethical permission was received from the Research Board of University (17-12-2018).
\end{abstract}

Keywords: learning co-creation; research ethics; research methodology; teacher leadership; research instrument.

\section{Acknowledgement}

The study is supported by the Research Project No. P-MIP-19-56; KOMOKO; financed by the Lithuanian Research Council. 